\title{
Development of Near Sea Surface Air Specific Humidity Retrieval by Satellite Remote Sensing
}

\author{
Zhuhui Jiang, Xiaobao You, Xin Yi \\ Beijing Institute of Applied Meteorology \\ Beijing, China \\ jiangzhuhui@163.com
}

\author{
Wei Zhang \\ Chinese satellite maritime monitoring and control department \\ Jiangyin, China
}

\begin{abstract}
Sea surface air specific humidity is important in the remote sensing of the Earth from space. First, the progress of satellite remote sensing near sea surface air specific humidity is studied, then, the principle of near sea surface ai specific humidity retrieval is illustrated; further research is suggested at last.
\end{abstract}

Index Terms-Remote sensing, near sea surface, air humidity.

\section{INTRODUCTION}

Water vapor in the atmosphere affects atmospheric radiation and thus atmospheric thermal equilibrium. It attenuates electromagnetic propagation through the atmosphere and, therefore, it is important in the remote sensing of the Earth from space. Since surface-level measurements are more available than upper-level ones, atmospheric scientists have long been interested in deriving the total water vapor in an atmospheric column with unit area, often referred to as the precipitable water $(W)$, from such surface-level measurements as dew-point temperature $\left(T_{d}\right)$, vapor pressure $(e)$ or mixing ratio $(r)[1]$. In the past it has been necessary to rely exclusively on in situ observations to estimate this important parameter. However, with the advent of satellite technology, we now have a unique and complementary way to remotely derive surface humidity. This is made possible because of the uniform spatial and temporal sampling provided by satellites. The principal issue with the satellite method, however, is that accurate estimations of near surface specific humidity $\left(Q_{a}\right)$ is not directly accessible from remote sensing measurements[2].

In this paper, the development of satellite remote sensing near sea surface air specific humidity will be studied. The retrieval of near sea surface air specific humidity based on radiosonde is introduced in section II. The retrieval of near sea surface air specific humidity based on satellite remote sensing is described in section III. The principle of near sea surface air specific humidity retrieval is illustrated in section IV. Conclusions are given in section $\mathrm{V}$.

\section{RETRIEVAL OF NEAR SEA SURFACE AIR SPECIFIC HUMIDITY BASED ON RADIOSONDES}

Recently Reitan[3] derived a linear relation between the logarithm of $W$ and $T_{d}$ using monthly-mean data from 15 stations in the continental United States over a period of 3 years, achieved a correlation of 0.98 between mean monthly total precipitable water and mean monthly surface dew point from a total of 540 observations. He found that the line of regression relating these mean values was of the form

$$
\ln W=A+B t_{d}
$$

where $W$ is precipitable water $(\mathrm{cm})$, td is the dew point temperature, $A=-0.981$ and $B=0.0341$. Reitan estimates the standard error from regression at 10 percent. This started a series of evaluations of the coefficients of this relation that lasted for more than a decade, with data coming mostly from weather stations over land. The above result prompted Bolsenga[4] to follow the same procedure to determine the regressional relations between mean daily and hourly observations of total water vapor content and surface dew point. Although the correlations he estimates are lower ( 0.85 to 0.80 for the mean daily and hourly observations, respectively), he found that the same basic relationship given by (1) exists. Bolsenga, however, estimates the coefficients of (1) to be $A=-$ 1.249 and $B=0.0427$ for the mean daily observations, and $A=-$ 1.288 and $B=0.0384$ for the hourly observations. Estimates of explained variance reveal that about 96 percent of the differences in total water vapor are related to differences in dew point for the mean monthly values, 72 percent for mean daily values and 64 percent for hourly values. Since a unique relationship between total water content and surface dew point depends on the variabìlity of the moisture profile, the tendency towards lower correlations with decreasing time intervals is to be expected. With each investigator working on his own limited set of data in different regions and on time scales from hourly to climatological seasonal mean (Smith, 1966), there is a lack of comprehensive evaluation or universal validation. A number of investigators remain skeptical of the accuracy and general applicability of such a relation suggested a global form of the humidity profile from which a relation between Wand $T_{d}$ can be derived. However, there is disagreement on its physical basis $[1,5,6]$.Ocean surface-level humidity is required in the determination of the ocean surface evaporation and the latent heat it carries. Due to the lack of data over much of the ocean area, only long-term mean distributions are available and not the month-to-month variability. Spaceborne sensors that would provide the much 
needed large-scale coverage do not measure $Q_{a}$. But spaceborne microwave radiometers can measure $W$ very well[7]; the accuracies were found to be comparable to those of radiosondes. A relation between $W$ and $Q_{a}$ is needed to apply satellite data in air-sea interaction studies. Over the ocean, the surface is spatially more homogeneous than over land, and the boundary layer, which holds most of the water vapor, is generally subjected to smaller diurnal change and less thermal buoyancy. The $Q_{a}-W$ relation over ocean may be quite different from that over land. In radiosonde reports from ocean stations, major variances in the atmospheric humidity sounding have time scales of less than a month, and the correlation between $W$ and $Q_{a}$ is very good when averaged over a month [8]. They suggested that a global statistical relation can be used to derive monthly-mean $Q_{a}$ from monthly-mean $W$ to an accuracy of $8 \times$ $10^{-4}$, or better than $20 \mathrm{~W} / \mathrm{m}^{2}$ in latent heat flux. They also demonstrated the application of such a relation in deriving $Q_{a}$ from $W$ measured by a spaceborne microwave radiometer.

\section{RETRIEVAL OF NEAR SEA SURFACE AIR SPECIFIC HUMIDITY BASED ON SATELLITE REMOTE SENSING}

Progress in this problem appeared in the pioneer study of Liu, who derived an empirical relationship between the total precipitable water $(W)$ from satellite microwave measurements SSM/I and near-surface specific humidity from radiosonde measurements (denoted as $Q_{a}-W$ relation), he select the radiosonde measurements data from the global monthly summaries of atmospheric soundings archived as Tape Deck (TD) 9648 at the National Climatic Data Center (NCDC) at Asheville, North Carolina. These stations have at least a few years of continuous data of reasonable quality[1]. Because of the inclusion of the $22 \mathrm{GHz}$ water vapor absorption line onboard the SSM/I, $W$ can be retrieved with great accuracy from this platform. Then, by using this empirical $Q_{a}-W$ relation in conjunction with satellite-derived surface wind speeds and sea surface temperature (SST), determination of latent heat flux over remote areas in the open oceans became feasible[9]. Unfortunately, errors in $Q_{a}$ originating from the $Q_{a}$-W relation can result in large errors in latent heat flux. This was shown by Esbensen et al.[10], who compared one year of latent heat flux derived from satellite data using the $Q_{a}-W$ relation and in situ estimates from the Comprehensive Ocean-Atmosphere Data Set observations. Their results showed systematic errors of over $2 \mathrm{~g} / \mathrm{kg}$ in the satellite estimates of monthly averaged $Q_{a}$, both in some tropical regions, as well as in middle and high latitudes. Other methods to estimate $Q_{a}$ from satellite data have been proposed in recent years. Wagner et al.[11] developed a procedure to derive $Q_{a}$ using $W$ from scanning multichannel microwave radiometer (SSMR), sea surface temperature, and vertical empirical orthogonal functions (EOF). The vertical EOFs were computed from specific humidity profiles from radiosonde data over seven regions in the Atlantic Ocean. Their retrieval algorithm shows root-mean-square (rms) values with collocated in situ data of $1.4 \mathrm{~g} / \mathrm{kg}$ for individual overpasses to about $0.8 \mathrm{~g} / \mathrm{kg}$ for monthly averages. Later, Schulz et al.[12] suggested the use of a four-channel regression to retrieve a boundary layer moisture estimate for the lowest $500 \mathrm{~m}$ that is linearly related to the surface humidity. They further developed a linear relationship between $W_{L}$ and $Q_{a}$ from radiosonde data and found an rms error of $1.5 \mathrm{~g} / \mathrm{kg}$ by comparison with collocated ship measurements of $Q_{a}$. This led Schluessel et al.[13] to use a direct five-channel regression of $Q_{a}$ to avoid a "propagation of errors," showing encouraging results. Bentamy et al. [14] also developed a direct four-channel retrieval of $Q_{a}$ using the same channels as the Schulz study. This was done in hopes of eliminating a possible seasonal bias the authors found in their comparisons. The stated root mean square error (rms) of this algorithm is approximately $1.4 \mathrm{~g} / \mathrm{kg}$. This is currently the algorithm of choice in the Hamburg Ocean Atmosphere Parameters and Fluxes from Satellite (HOAPS) product. Chou et al.[15] used SSM/I daily averaged $W, W_{L}$ retrieved according to Schulz et al.[12], and an EOF procedure to estimate daily averages of $Q_{a}$. Their approach included six classes of $W$-based categories of EOF, which are independent of geographical locations. Comparison with radiosonde data indicated an accuracy of $1.7 \mathrm{~g} / \mathrm{kg}$ for $Q_{a}$ daily averages. Miller et al.[16], on the other hand, developed a polynomial fit that estimates the difference between the saturation specific humidity $\left(Q_{s}\right)$ and air specific humidity $\left(Q_{a}\right), Q_{s}-Q_{a}$, as a function of $W$ and SST. The rms values for $Q_{s}-Q_{a}$ for their linear regressions range from 1.96 to $2.01 \mathrm{~g} / \mathrm{kg}[2]$.

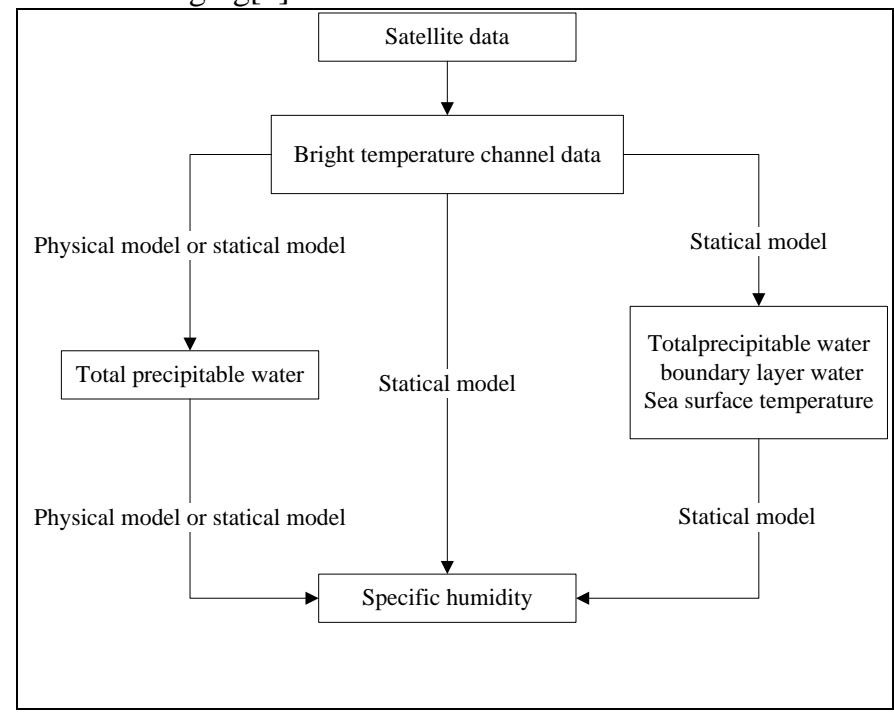

Fig.1. Methods to retrieve specific humidity.

In a study by Jackson et al.[17], a stepwise regression technique using combined instruments was found to improve the accuracy of the retrieval, primarily from the inclusion of the Advanced Microwave Sounding Unit-A (AMSU-A) 52.8 $\mathrm{GHz}$ channel that has a peak weighting in the lower troposphere. This study also mentions the impact of high cloud liquid water (CLW) contents on the $37 \mathrm{GHz}$ channels as seen from radiative transfer model simulations. Unfortunately, AMSU-A data only extends from late 1998; for the use of algorithms for longer time scales, SSM/I-only retrievals are necessary. Singh et al.[18] used the Genetic algorithm to find the empirical function relating the input ( $W$, boundary layer water $W_{b}$, and SST) and output $Q_{a}$. The input data consist of 2 years of daily $W, W_{b}$, from SSM/I, and SST data from AVHRR. COADS (Comprehensive Ocean Atmospheric Data Set) 
observations of $Q_{a}$ are used to develop and evaluate the new methodology. The performance of the algorithm is measured with COADS observations, which are not used in the development phase. The global mean rms error for daily averages $Q_{a}$ is approximately $1.5 \pm 0.40 \mathrm{~g} / \mathrm{kg}$. Roberts et al.[19] predicted the near surface atmospheric variables from SSM/I using neural networks with a first guess approach, and the rms error of $Q_{a}$. is approximately $1.3 \mathrm{~g} / \mathrm{kg}$.

Based on the relationship between total precipitable water and surface relative humidity[21, 22, 23], $\mathrm{Wu}$ et al.[24] developed a statistical relations between the AMSR-E bright temperature data and sea surface meteorological parameters with multi-parameters regression method. The retrieved results in the Pacific Ocean near the equator were compared with the data observed by TAO buoys. Their root mean square errors are $0.53 \mathrm{~K}(\mathrm{SST}), 0.74 \mathrm{~K}\left(T_{a}\right), 3.20 \%$ (relative humidity) and $1.1 \mathrm{~m} / \mathrm{s}$ (wind speed), respectively. Wang et al.[25] compared AMSR-E and TAO buoy data using genetic algorithm, the rms differences are $1.18 \mathrm{~K}$ and $1.36 \mathrm{~g} / \mathrm{kg}$ for air temperature and specific humidity respectively. Methods to retrieve specific humidity are shown in Fig.1, and the development of remote sensing near sea surface air humidity is illustrated in table I.

\section{THE PRINCIPLE OF NEAR SEA SURFACE AIR SPECIFIC HUMIDITY RETRIEVAL}

Ordinarily the moisture content is greatest at the earth's surface and decreases to a value of zero at the top of the atmosphere. Regardless of the exact moisture profile, width the proper choice of a power $\lambda$ for a given atmospheric situation, the average decrease of moisture through the entire atmospheric column may be described by the power law $[6,26]$

$$
r=r_{a}\left(p / p_{0}\right)^{\lambda}
$$

From the definition of the vertical mean mixing ratio $\bar{r}$,

$$
\bar{r}=\frac{1}{p_{0}} \int_{0}^{p_{0}} r_{a}\left(\frac{p}{p_{0}}\right)^{\lambda} d p=\frac{r_{a}}{\lambda+1},
$$

$W$ can be described as

$$
W=g^{-1} \int_{0}^{p_{0}} Q d p
$$

\begin{tabular}{|c|c|c|c|c|c|}
\hline \multicolumn{2}{|c|}{\begin{tabular}{|l|} 
Data Source \\
\end{tabular}} & Authors(Year) & Method & Data Type & Main Conclusion \\
\hline \multirow{5}{*}{\multicolumn{2}{|c|}{ Radiosonde }} & Reitan(1963) & Linear regression & Monthly averaged & $\begin{array}{l}\text { A linear relation between the logarithm of } W \\
\text { and } T_{d} \text { is derived. }\end{array}$ \\
\hline & & Bolsenga(1965) & Linear regression & $\begin{array}{l}\text { Daily averaged } \\
\text { Hourly averaged }\end{array}$ & $\begin{array}{l}\text { The tendency towards lower correlations } \\
\text { between } W \text { and } t_{d} \text { with decreasing time } \\
\text { intervals. }\end{array}$ \\
\hline & & Smith(1966) & Physical mode & Monthly averaged & $\begin{array}{l}\text { Reitan's relation in different regions and on } \\
\text { time scales is evaluated. }\end{array}$ \\
\hline & & Viswanadham(1981) & Linear regression & Monthly averaged & $\begin{array}{l}\text { Smith's coefficient in the southern hemisphere } \\
\text { is developed. }\end{array}$ \\
\hline & & Liu(1986) & Linear regression & Monthly averaged & Mixing ratio error: $8 \times 10^{-4}$ \\
\hline \multirow{13}{*}{$\begin{array}{l}\text { Satellite } \\
\text { Remote } \\
\text { Sensing }\end{array}$} & Nimbus-5 & $\begin{array}{l}\text { Staelin et al.(1976) } \\
\text { Chang et al.(1979) }\end{array}$ & Statistical regression & Individual overpasses & $\begin{array}{l}22 \mathrm{GHz} \text { and } 183 \mathrm{GHz} \text { can be used to retrieve } \\
\text { water vapor content. }\end{array}$ \\
\hline & AMMS & Wang et al.(1989) & Statistical regression & Individual overpasses & $\begin{array}{l}92 \mathrm{GHz} \text { can be used to retrieve water vapor } \\
\text { content. }\end{array}$ \\
\hline & SSMR & Wagner et al. (1990) & EOF method & $\begin{array}{l}\text { Monthly averaged } \\
\text { Individual overpasses }\end{array}$ & $\begin{array}{l}Q_{a} \text { monthly averaged rms: } 0.8 \mathrm{~g} / \mathrm{kg} \\
Q_{a} \text { individual overpasses } \mathrm{rms}: 1.4 \mathrm{~g} / \mathrm{kg} \text {. }\end{array}$ \\
\hline & SSM/I 4 channels & Schulz et al. (1993) & Statistical regression & Individual overpasses & $\begin{array}{l}\text { They use of a four-channel regression to } \\
\text { retrieve a boundary layer moisture estimate for } \\
\text { the lowest } 500 \mathrm{~m} \text { that is linearly related to the } \\
\text { surface humidity. }\end{array}$ \\
\hline & SSM/I 5 channels & Schluessel et al. (1995) & Statistical regression & Individual overpasses & SSM/I data can retrieve $Q_{a}$. \\
\hline & $\mathrm{SSM} / \mathrm{I}$ & Chou et al. (1995) & EOF method & Daily averaged & $Q_{a}$ daily averaged $\mathrm{rms}: 1.7 \mathrm{~g} / \mathrm{kg}$ \\
\hline & SSM/I & Miller et al. (1992) & Polynomial regression & Individual overpasses & $Q_{s}-Q_{a} \mathrm{rms}: 2.01 \mathrm{~g} / \mathrm{kg}$. \\
\hline & SSM/I 4 channels & Bentamy et al. (2003) & Statistical regression & Individual overpasses & $Q_{a}$ individual overpasses rms:1.4 g/kg. \\
\hline & $\begin{array}{l}\text { AMSU-A } \\
\text { SSM/I } \\
\text { SSM/T-2 }\end{array}$ & Jackson et al. (2006) & $\begin{array}{l}\text { Multi-sensor data } \\
\text { regression }\end{array}$ & 5 days averaged & $Q_{a} 5$ days averaged rms:0.83g $/ \mathrm{kg}$. \\
\hline & $\begin{array}{l}\text { SSM/I } \\
\text { AVHRR }\end{array}$ & Singh et al. (2006) & Genetic algorithm & Individual overpasses & $\begin{array}{l}\text { The relation between SST and } Q_{a} \text { is evaluated. } \\
Q_{a} \text { relative humidity rms:1.5 } \pm 0.40 \mathrm{~g} / \mathrm{kg} \text {. }\end{array}$ \\
\hline & AMSR-E & Wu et al. (2007) & $\begin{array}{l}\text { Multi-parameter } \\
\text { regression }\end{array}$ & Individual overpasses & $Q_{a}$ relative humidity rms: $3.2 \%$. \\
\hline & AMSR-E & Wang et al. (2009) & Genetic algorithm & Individual overpasses & $Q_{a}$ individual overpasses rms: $1.36 \mathrm{~g} / \mathrm{kg}$. \\
\hline & $\begin{array}{l}\text { SSM/I } \\
\text { OISST }\end{array}$ & Roberts et al. (2010) & Neural networks & Individual overpasses & $Q_{a}$ individual overpasses rms: $1.3 \mathrm{~g} / \mathrm{kg}$. \\
\hline
\end{tabular}

TABLE I. Development of Remote Sensing Near Sea SuRface Air Humidity 
Due to $r \approx Q$, so $W=p_{0} \bar{r} / g$, and then

$$
W=W\left(Q_{a}\right)=\frac{p_{0} Q_{a}}{g(\lambda+1)},
$$

(5) is the principle of near sea surface air specific humidity retrieval.

\section{CONCLUSIONS}

In this paper, the progress of satellite remote sensing near sea surface air specific humidity is studied, and the principle of near sea surface air specific humidity retrieval is illustrated. Further research can be carried out in three aspects: 1. Multisensor can be used to improve specific humidity. 2. SST and wind speed should be introduced to retrieve the specific humidity. 3. Latent and sensible heat fluxes calculation may be improved. Specific humidity, wind speed and SST relate to the turbulent latent and sensible heat fluxes over the world oceans, and are important components of the global energy budget, an accurate specific humidity can improve latent and sensible heat fluxes calculation.

\section{REFERENCES}

[1] W. T. Liu, "Statistical relation between monthly mean precipitable wager and surface-level humidity over global oceans," Mon. Wea. Rev., 1986, 114, 1591-1602.

[2] C. Jones, P. Peterson, and C. Gautier, "A new method for deriving ocean surface specific humidity and air temperature: An artificial neural network approach," J. Appl. Meteorol., 1999, $38,1229-1246$.

[3] C. H. Reitan, "Surface dew point and water vapor aloft," J. Appl. Meteor., 1963, 2, 776-779.

[4] S. J. Bolsenga, "The relationship between total atmospheric water vapor and surface dew point on a mean daily and hourly basis," J. Appl. Meteor., 1965, 4, 430-432.

[5] L. Berkofsky, "Comments on Note on the relationship between total precipitable water and surface dew point," J. Appl. Meteor., 1967, 6, 959-960.

[6] W. L. Smith, "Note on the relationship between total precipitable water and surface dew point," J. Appl. Meteor., 1966, 5, 726-727.

[7] A. T. C. Chang, and T. T. Wilheit, "Remote sensing of atmospheric water vapor, liquid water, and wind speed at the ocean surface by passive microwave techniques from Nimbus-5 satellite," Radio Sci., 1979, 14, 793-802.

[8] W. T. Liu, and P. P. Niiler, "Determination of monthly mean humidity in the atmospheric surface layer over oceans from satellite data," J. Phys. Oceanogr., 1984, 14, 1451-1457.

[9] T. W. Liu, "Moisture and latent heat flux variabilities in the tropical Pacific derived from satellite data," J. Geophys. Res., 1988, 93, 6749-6760.

[10] S. K. Esbensen, D. B. Chelton, D. Vockers, and J. Sun, “An analysis of errors in Special Sensor Microwave Imager evaporation estimates over the global oceans," J. Geophys. Res., 1993, 98, 7081-7101.

[11] D. Wagner, E. Ruprecht, and C. Simmer, "A combination of microwave observations from satellites and EOF analysis to retrieve vertical humidity profiles over the ocean," J. Appl. Meteor., 1990, 29, 1142-1159.

[12] J. P. Schulz, and H. Grassl, "Water vapor in the atmospheric boundary layer over oceans from SSM/I and AVHRR measurements," J. Remote Sens., 1993, 14, 2773-2789.

[13] P. Schluessel, L. Schanz, and G. Englisch, "Retrieval of latent heat flux and longwave irradiance at the sea surface from SSM/I and AVHRR measurements," Adv. Space Res., 1995, 16, 1010710116.

[14] A. Bentamy, K. B. Katsaros, A. M. Mestas-Nunez, W M. Drennan, E. B. Forde, and H. Roquet, "Satellite estimates of wind speed and latent heat flux over the global oceans," J.Clim., 2003, 16, 637-656.

[15] S. Chou, R. M. Atlas, C. Shie, and J. Ardizzone,: Estimates of surface humidity and latent heat fluxes over oceans from SSM/I data," Mon. Wea. Rev., 1995, 123, 2405-2425.

[16] D. K. Miller, and K. B. Katsaros, "Satellite-derived surface latent heat fluxes in a rapidly intensifying marine cyclone," Mon. Wea. Rev., 1992, 120, 1093-1107.

[17] D. L. Jackson, G. A. Wick, and J. J. Bates, "Near-surface retrieval of air temperature and specific humidity using multisensor microwave satellite observations," J. Geophys. Res., 2006, 111, D10306, doi:10.1029/2005JD006431.

[18] R. Singh, P. C. Joshi, C. M. Kishtawal, and P. K. Pal, “A new method for estimation of near surface specific humidity over global oceans," Meteorol. Atmos. Phys., 2006, 94, 1-10.

[19] J. B. Roberts, C. A. Clayson, F. R. Robertson, and D. L. Jackson, "Predicting near-surface atmospheric variables from Special Sensor Microwave/Imager using neural networks with a firstguess approach," J. Geophys. Res., 2010, 115, D19113, doi:10.1029/2009JD013099.

[20] M. Estoque, "A graphically integrable prediction model incorporating orographic influences," J. Meteor., 1957, 17, 293296.

[21] Y. Viswanadham, "The relationship between total precipitable water and surface dew point," J. Appl. Meteor., 1981, 20, 3-8.

[22] D. H. Staelin, K. F. Kunzi, and R. L. Pettyjohn, "Remote sensing of atmospheric water vapor and liquid water with the Nimbus-5 microwave spectrometer," J. Appl. Meteor., 1976, 15, 1204-1214.

[23] J. R. Wang, T. T. Wilheit, and L. A. Chang, "Retrieval of total precipitable water using Radiometric measurements near 92 and 183GHz," J. Appl. Meteor., 1989, 28, 146-154.

[24] Y. Wu, Y. He, and B. Zhang, "Real-time sea surface meteorological parameters retrieved from AMSR-E a case," Chinese High Technology Letters, 2007, 17, 633-637.(in Chinese)

[25] L. Wang, Y. He, and B. Zhang, "Retrieval of near surface air temperature and specific humidity based on AMSR-E satellite data," Marine Sciences, 2009, 30, 20-24. (in Chinese)

[26] G. L. Stephens, "On the relationship between water vapor over the oceans and sea surface temperature," J. Clim., 1990, 3, 634645 . 